\title{
Transcatheter Arterial Embolization for Intra-abdominal Bleeding
}

\author{
Stephen D. Gill'-4,@ Stephanie Dawson ${ }^{1} \quad J e s s i e-A n n e ~ K e n w o r t h y{ }^{1} \quad J a r r o d ~ G r e e n h a l g h^{1} \quad$ Andrew Hely ${ }^{1,2}$ \\ Benjamin Harrison ${ }^{1,2}$ Steve Landers ${ }^{1,2}$
}

${ }^{1}$ Barwon Medical Imaging, Barwon Health, Geelong, Australia

${ }^{2}$ GIRADI Research Institute, Geelong, Australia

${ }^{3}$ School of Medicine, Deakin University, Victoria, Australia

${ }^{4}$ Barwon Centre for Orthopaedic Research \& Education (B-CORE),

St John of God Hospital, Geelong, Australia
Address for correspondence Stephen Gill, PhD, Barwon Medical Imaging, University Hospital Geelong, Bellerine Street, Geelong, Australia, 3220 (e-mail: steveg@barwonhealth.org.au).

J Clin Interv Radiol ISVIR 2019;3:12-18

\begin{abstract}
Purpose Transcatheter arterial embolization (TAE) is increasingly used for managing hemorrhage. The evidence-base supporting the procedure is accumulating. This study investigated the safety and effectiveness of TAE for intra-abdominal bleeding at a large regional public health service in Australia.

Materials and Methods Medical records of all patients undergoing TAE for intra-abdominal bleeding over a 7-year period were retrospectively reviewed, excluding gastric bleeding. Data were extracted into a standardized electronic data collection tool. Technical success of TAE was defined as cessation of active contrast media extravasation on post-procedure angiography. Complications were categorized as intra- and post-procedure. The severity of complications was rated according to the Society of Interventional Radiology Standards of Practice Committee Classifications of Complications by Outcome.

Results Ninety-two cases were identified. TAE was technically successful in 70 (94.6\%) of the 74 cases when visible contrast media extravasation was evident during angiograph. During procedures, six minor complications occurred such as transient symptomatic hypotension or moderate to severe abdominal pain. Following procedures, eight minor complications were reported: seven cases of hematoma at the catheter access point and one case of contrast reaction. One major complication,

Keywords

- embolization

- abdomen/ gastrointestinal

- hemorrhage bowel ischemia requiring hemicolectomy, occurred post-TAE for a bleeding cecal aneurysm; however, widespread arterial spasm was noted on angiography prior to TAE and interventional colonoscopy had occurred 2 days prior to TAE, suggesting that ischemia was not primarily due to TAE.

Conclusion This study supports the use of TAE for a diverse range of cases of intra-abdominal bleeding. TAE produced high rates of complete hemostasis with few complications.
\end{abstract}

\section{Introduction}

Acute intra-abdominal bleeding can be treated with various modalities including conservative medical management, endoscopic coagulation, vasopressin infusion, therapeutic transcatheter embolization, and surgery. ${ }^{1}$ Endoscopy is

${ }^{\odot}$ Dr. Gill's ORCID ID is http://orcid.org/0000-0001-8722-0572.

received

November 13, 2018

accepted

December 24, 2018

published online

April 22, 2019 the primary invasive technique for diagnosing and treating gastrointestinal (GI) bleeding. ${ }^{1,2}$ Transcatheter arterial embolization (TAE) is an alternative to surgery for patients for whom endoscopic therapy has failed or is not possible. ${ }^{3,4}$

The use of TAE is increasing due to improvements in catheter technology, development of new materials for embolotherapy, and wider availability of appropriately skilled interventional radiologists. ${ }^{2}$ Some authors suggest,

(C)2019 by Indian Society of

Vascular and Interventional Radiology
License terms

() (1) $\ominus \circledast$ 
based on emerging evidence, that radiologic imaging and endovascular treatment is now the preferred option for GI bleeding compared with open surgery due to lower morbidity and mortality, though multidisciplinary consensus between gastroenterologists, radiologists, and surgeons should precede TAE. ${ }^{5,6}$

A systematic review investigating the effectiveness of TAE for lower GI bleeding reported that embolization was successful in $85 \%$ of patients at 1 month for diverticulosis-related bleeding, and $55 \%$ of patients for non-diverticulosis-related bleeding. ${ }^{7}$ Regarding nonvariceal upper GI bleeding, a systematic review found that bleeding stopped immediately in 52 to $100 \%$ of cases and rebleeding occurred in 0 to $55 \%$ of cases within 30 days. ${ }^{2}$ The studies in both systematic reviews were observational, mostly retrospective and usually with small sample sizes.

Complications during or following TAE include ischemia and/or infarction secondary to reduced blood flow to the segment of organ supplied by the target vessel or inadvertent embolization of nontarget vessels, acute kidney injury, or injury to the access artery such as dissection, perforation, pseudoaneurysm, and vasospasm. ${ }^{2,6-8} \mathrm{Hematoma}$ at the artery access site is a common minor complication. ${ }^{6}$ Complication rates reported in the literature have reduced over time, reportedly due to improvements in catheters and embolic agents that permit "superselective microembolization" of target vessels..$^{2,89}$ For example, ischemia, the second most common complication following TAE after hematoma at the access site, ${ }^{2}$ was reported in 21 to $33 \%$ of cases in the 1990 s (see Khanna et $\mathrm{al}^{7}$ for summary) compared to 1 to $4 \%$ in two more recent studies (see State and Gralnek ${ }^{4}$ for summary).

The use of TAE is increasing, yet the evidence-base supporting its use is still developing. This study aimed to contribute to a growing body of evidence regarding TAE by investigating the use of TAE at a large regional tertiary public health service. Specifically, we sought to determine the safety and effectiveness of TAE for abdominal bleeding, excluding gastric bleeding, which was predominantly managed via endoscopy at our service.

\section{Materials and Method}

\section{Study Design}

This study is a single-site retrospective audit of all patients receiving TAE for abdominal bleeding, excluding gastric bleeding, between 2009 and 2015 .

\section{Setting}

This study was conducted at a large regional public health service in Australia, which provides a comprehensive suite of services excluding organ transplantation and neurosurgery. The radiologist's decision to proceed with TAE is made with reference to appropriate guidelines ${ }^{10}$ and in collaboration with relevant teams such as gastroenterology, general surgery, intensive care, and emergency departments. TAE has occurred at the study site for more than 25 years.

\section{Data Extraction and Analysis}

Patients who received TAE for GI bleeding between January 1, 2009 and December 31, 2015 were considered for the study. The data collection period was chosen to coincide with when the organization commenced using a digital medical record, which enabled rapid access to each patient's medical record. All patients who were coded by the organization's Information Services Department as receiving "transcatheter TAE of blood vessels, abdomen" during an admission were screened for eligibility. Patients were subsequently excluded if they had received TAE for selective internal radiation therapy (SIRT), transcatheter arterial chemoembolization (TACE), and TAE for gastric bleeding. Retroperitoneal hemorrhages and endoleaks were included. Prior to TAE, all patients received computed tomographic angiogram (CTA) to determine the presence and location of bleeding. Only cases with positive CTA proceeded to TAE.

Patients' medical records were inspected by one of three researchers (S.D., J.A.K., and J.G.). Each researcher was arbitrarily assigned one-third of the cases for independent review. Once all cases were reviewed, each researcher then inspected the cases reviewed by another researcher by comparing each patient's medical record with the extracted data. Discrepancies were resolved by discussion between the researchers and arbitrated by other researchers (S.L., B.H., and S.G.) when resolution could not be achieved.

Data were collected and managed using REDCap, an electronic data management tool hosted at the study organisation. ${ }^{11}$ Variables of interest included age, sex, date of TAE, length of hospital admission, indication for embolization, interventionalist, embolic agent, vascular region embolized, technical success, ongoing bleeding post-procedure and/or complication, and severity of complication. Vascular region embolized was categorized as celiac artery origin, superior mesenteric artery origin, inferior mesenteric artery origin, iliac artery origin, renal artery origin, or femoral artery origin. Technical success was defined as cessation of active contrast media extravasation on post-procedure angiography. Complications and adverse events were categorized as intra- or post-procedure. Intraprocedure events occurred in the angiography suite during or immediately after TAE. Post-procedure adverse events occurred during the admission and were categorized as ongoing signs or symptoms of abdominal bleeding requiring invasive procedure (e.g., surgery), infection or hematoma at the catheter access site, contrast-induced nephropathy or allergic reaction, GI ischemia, and/or infarction requiring surgery. Readmission to our hospital within 30 days of discharge and/or death within 3 months of TAE were also assessed. Adverse events were subsequently assessed as to whether TAE was the direct cause. The severity of complications that were directly related to TAE were rated according to the Society of Interventional Radiology (SIR) Standards of Practice Committee Classifications of Complications by Outcome. ${ }^{12}$ 


\section{Statistical Analysis}

Data were analyzed with descriptive statistics such as the number and proportion of events using Microsoft Excel version 16.16.3 (Microsoft Corp.).

\section{Ethical Considerations}

The organization's Human Research Ethics Committee (HREC) approved the study (HREC reference 15/48).

\section{Results}

\section{Patients}

Ninety-two cases were included in the analysis ( - Fig. $\mathbf{1}$ ). Patient demographic details are mentioned in - Table $\mathbf{1 .}$ Diverticulosis was the most commonly reported comorbidity associated with bleeding.

Eight patients had a gastroscopy, colonoscopy, or cystoscopy prior to TAE to investigate the source of bleeding.
Two of these patients received an intervention during the scope to arrest bleeding including adrenalin, argon plasma coagulation (APC), or resolution clips that resolved bleeding at the time of scope, but subsequently patients had ongoing signs of bleeding.

\section{Interventions}

Four interventional radiologists completed 90 (97.8\%) procedures; the remaining two cases were completed by vascular surgeons. On average, one procedure per month was conducted over the study duration. In 2009 and 2010, eight and six procedures were completed, respectively. From 2011 to 2015,13 to 19 procedures were completed each year. The most commonly embolized vascular regions included the superior mesenteric artery $(n=31,33.7 \%)$, inferior mesenteric artery $(n=22,23.9 \%)$, and coeliac artery $(n=17,18.5 \%)$ (-Table 2). Coils were the most commonly used embolic agents ( $n=86,93.5 \%$ of cases).

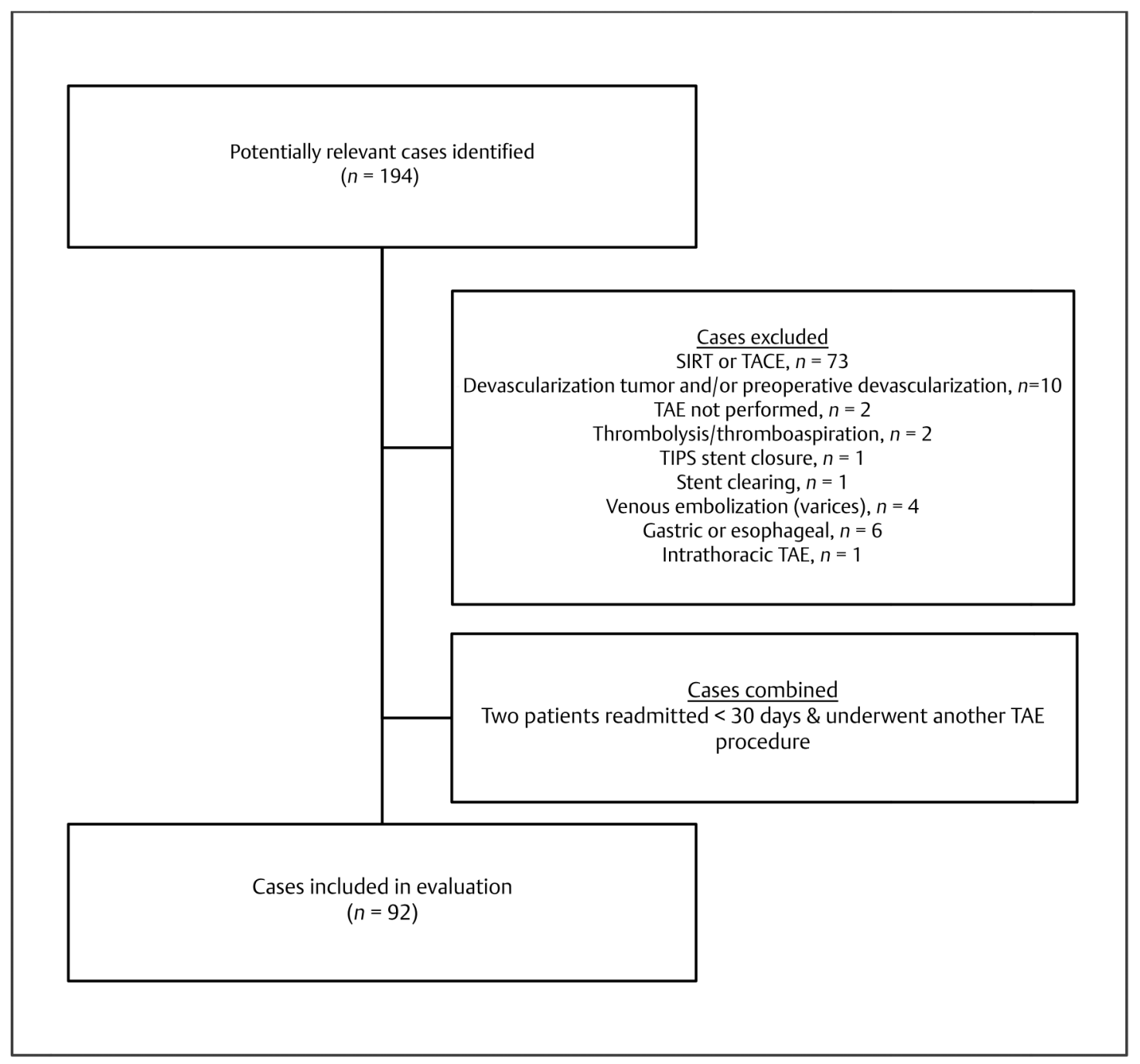

Fig. 1 Flowchart for case inclusion in this study. SIRT, selective internal radiation therapy; TACE, transcatheter arterial chemoembolization; TAE, transcatheter arterial embolization; TIPS, transjugular intrahepatic portosystemic shunt. 
Table 1 Participant characteristics

\begin{tabular}{|l|l|}
\hline Characteristic $(\boldsymbol{n}=\mathbf{9 2})$ & $\mathbf{N}(\%)$ \\
\hline Age (average, SD) & $69.9(16.7)$ \\
\hline Female (\%) & $31(33.7)$ \\
\hline Length of hospital admission (average days, SD) & $10.3(15.6)$ \\
\hline $\begin{array}{l}\text { Primary condition/event associated with } \\
\text { bleeding }\end{array}$ & \\
\hline Diverticulosis & $28(30.4)$ \\
\hline Tumor (bleeding) & $12(13.0)$ \\
\hline Trauma & $9^{\text {a }}(9.8)$ \\
\hline Postoperative/post-procedure bleeding & $13^{\text {b }(14.1)}$ \\
\hline Aneurysm & $10(10.9)$ \\
\hline Therapeutic anticoagulation & $5(5.4)$ \\
\hline Angiodysplasia & $5(5.4)$ \\
\hline Endoleak & $4(4.3)$ \\
\hline Other & $6(6.5)$ \\
\hline
\end{tabular}

Abbreviation: SD, standard deviation.

aSpleen $(n=6)$, kidney $(n=1)$, liver $(n=1)$, pelvis $(n=1)$.

${ }^{b}$ Colonscopy and/or polypectomy $(n=5)$, perforated colon during colonoscopy $(n=1)$, renal biopsy $(n=2)$, percutaneous nephrolithotomy $(n=2)$, laparoscopic cholecystectomy $(n=1)$, hemorrhoidal banding $(n=1)$, hemicolectomy for necrotizing enterocolitis $(n=1)$. cNecrotizing pancreatitis $(n=1)$, splenic rupture in the setting of chronic pancreatitis $(n=1)$, no associated condition/event apparent/ recorded $(n=4)$.

\section{Technical Success}

Technical success was reported in 70 (76.1\%) cases; the interventionalist indicated cessation of bleeding on angiogram following TAE (-Table 3). In 18 (19.6\%) cases, a definitive site of bleeding was not apparent on angiography prior to TAE, and cessation of bleeding post-TAE, according to our definition, was not possible. Therefore, TAE was technically successful in $94.6 \%$ ( 70 of 74 ) of cases when visible contrast media extravasation was evident during angiograph. In four $(4.3 \%)$ cases, technical success was not achieved: (1) the procedure was abandoned due to an intraprocedural complication ( $n=1$, see "Intraprocedural Events" for details); (2) minor extravasation persisted and further TAE was not completed due to the interventionalist's concern of ischemia ( $n=2$, both patients had ongoing symptoms and subsequent surgery); and (3) two of three offending vessels were successfully embolized, but the third vessel could not be accessed and embolized ( $n=1$, bleeding resolved with conservative management).

\section{Repeat Angiography}

Thirteen (14.1\%) patients had repeat angiography that occurred 0 to 28 days following the initial procedure (-Table 2). For 10 patients, the initial procedure successfully arrested extravasation, but ongoing signs of bleeding were present for which repeat TAE was deemed appropriate and was subsequently technically successful. For two patients, no TAE occurred at the time of initial
Table 2 Interventions

\begin{tabular}{|c|l|}
\hline Intervention $(\boldsymbol{n}=\mathbf{9 2})$ & N cases (\%) \\
\hline Embolic agent $^{\mathrm{a}}$ & \\
\hline Coils (Cook Medical) & $86(93.5)$ \\
\hline PVA (Cook Medical) & $11(12.0)$ \\
\hline Gelfoam (Ethicon) & $2(2.2)$ \\
\hline Vascular plug (Amplatzer) & $3(3.3)$ \\
\hline Arterial branch embolized & \\
\hline Superior mesenteric origin & $31(33.7)$ \\
\hline Inferior mesenteric origin & $22(23.9)$ \\
\hline Coeliac origin & $17(18.5)$ \\
\hline Renal origin & $15(16.3)$ \\
\hline Iliac origin & $6(6.5)$ \\
\hline Femoral origin & 0 \\
\hline Lumbar origin & $3(3.3)$ \\
\hline Technical success & \\
\hline Bleeding ceased on angiogram & $70(76.1)$ \\
\hline Bleeding partially controlled & $3(3.3)$ \\
\hline No bleeding found & $18(19.6)$ \\
\hline Repeat angiography performed & $13(14.1)$ \\
\hline Repeat TAE successful & 9 c (69.2) \\
\hline
\end{tabular}

Abbreviations: PVA, polyvinyl alcohol; TAE, transcatheter arterial embolization.

${ }^{a}$ More than one embolic agent could be used, or more than one vessel embolized.

'TAE proceeded based on preprocedural CTA findings.

${ }^{c} n=9$ does not include no TAE performed $(n=3)$, sluggish residual flow persisted in one case that was managed conservatively.

Table 3 Intra- and post-procedural events

\begin{tabular}{|l|l|}
\hline Event $(\boldsymbol{n}=\mathbf{9 2})$ & $\mathbf{N}(\%)$ \\
\hline Intraprocedural events & $6(6.5)$ \\
\hline Postprocedural events & \\
\hline $\begin{array}{l}\text { Ongoing bleeding requiring invasive } \\
\text { procedure }\end{array}$ & $3(3.3)$ \\
\hline Infection at catheter access point & 0 \\
\hline Hematoma at catheter access point & $7(7.6)$ \\
\hline Contrast reaction & $1(1.1)$ \\
\hline GIT ischemia or infarction & $1(1.1)$ \\
\hline Readmission within 30 days & $16(17.4)$ \\
\hline Due to ongoing bleeding & $7(7.6)$ \\
\hline Death within 3 months of TAE & $14(15.2)$ \\
\hline Due to TAE & $0^{\text {a }}$ \\
\hline
\end{tabular}

Abbreviations: GIT, gastrointestinal tract; TAE, transcatheter arterial embolization.

ane patient was recorded within the hospital database as having died 8 days post discharge from hospital, but the cause of death was not recorded; the patient's primary diagnosis was metastatic non-small cell lung cancer. 
angiography: (1) no bleeding was found ( $n=1)$, but symptoms persisted, so a coil was deployed on repeat angiography in the area corresponding to the site of bleeding on CTA, though no extravasation of contrast was evident; and (2) an intraprocedural complication occurred $(n=1)$, so the procedure was aborted and reattempted the following day (see "Intraprocedural Events"). For one patient, a minor degree of extravasation persisted, and further TAE did not occur due to the risk of ischemia. Repeat angiography 2 days later did not identify an offending vessel, and no TAE occurred. The patient subsequently had small bowel resection and pancreas necrosectomy, which was not a complication of the TAE or repeat angiography.

\section{Complications and Adverse Events Intraprocedural Events}

Six intraprocedural events were reported ( - Table 3 ): (1) symptomatic hypotension $(n=3)$ that was successfully treated with intravenous fluids; (2) moderate to severe abdominal pain $(n=2)$ that settled with analgesia; and (3) loss of control of a coil $(n=1)$ that prolapsed into the main descending branch of the right renal artery that maintained flow during the remainder of the procedure and no further complications occurred. In one case of hypotension, the procedure was paused because the patient urgently needed to relieve his bowels, and while opening his bowels, he became hypotensive and unresponsive. The procedure was abandoned, and the patient recovered with fluid resuscitation. Upon repeating the procedure the following day, no TAE was performed as the target area could not be accessed due to arterial spasm and dissection. Sigmoidoscopy 2 days post initial angiogram revealed patch of ischemic mucosa at splenic flexure $(5 \times 5 \mathrm{~cm})$, which was not actively treated. The patient was discharged home 5 days after initial angiography. All intraprocedural events are considered minor complications according to SIR classifications.

\section{Postprocedural Events}

The type and frequency of postprocedural adverse events and complications are listed in - Table 3. All complications directly attributable to TAE were considered minor according to the SIR classification.

One patient was reported to have contrast-induced nephropathy, but urine output had normalized by discharge from hospital 5 days later. Seven patients had a hematoma at the cannula access site, all of which were relatively minor and required no ongoing management. Three patients were transferred to another hospital shortly after TAE, and their postprocedural outcomes are unknown.

\section{Ongoing Bleeding Requiring Surgery}

Three patients had a surgical procedure for recurrent bleeding following TAE (see - Table 4 for details). None of these cases had a direct complication of TAE.

Six patients were readmitted with ongoing bleeding within 30 days of discharge. Two of them received repeat TAE and were considered as continuous cases in our
Table 4 Three patients who required surgery post-TAE for ongoing bleeding

\begin{tabular}{|c|c|c|}
\hline $\begin{array}{l}\text { Case: TAE } \\
\text { indication }\end{array}$ & TAE procedural details & $\begin{array}{l}\text { Surgical details } \\
\text { post-TAE }\end{array}$ \\
\hline $\begin{array}{l}\text { 1. Melena } \\
\text { due to } \\
\text { active } \\
\text { bleeding } \\
\text { superior } \\
\text { mesenteric } \\
\text { artery } \\
\text { branch. } \\
\text { Associated } \\
\text { pancreatitis. }\end{array}$ & $\begin{array}{l}\text { TAE of three ileal } \\
\text { branches of the } \\
\text { superior mesenteric } \\
\text { artery with multiple } \\
\text { 2-5 mm coils. A minor } \\
\text { degree of extravasation } \\
\text { persisted within the } \\
\text { ileum and further TAE } \\
\text { was avoided due to per- } \\
\text { ceived risk of significant } \\
\text { mesenteric ischemia. }\end{array}$ & $\begin{array}{l}\text { Laparotomy, small } \\
\text { bowel resection, } \\
\text { pancreas necro- } \\
\text { sectomy with end } \\
\text { ileostomy for acute } \\
\text { severe necrotizing } \\
\text { pancreatitis and } \\
\text { ongoing small } \\
\text { bowel bleeding. } \\
\text { Occurred } 3 \text { days } \\
\text { post-TAE. }\end{array}$ \\
\hline $\begin{array}{l}\text { 2. Bleeding } \\
\text { from } \\
\text { ileostomy } \\
\text { following } \\
\text { hemicol- } \\
\text { ectomy for } \\
\text { necrotizing } \\
\text { enterocolitis. } \\
\text { Associated } \\
\text { acute } \\
\text { myeloid } \\
\text { leukemia. }\end{array}$ & $\begin{array}{l}\text { Three angiographies } \\
\text { were completed over } \\
\text { a 7-day period. TAE of } \\
\text { distal branch of ileocol- } \\
\text { ic artery was conducted } \\
\text { on second angiogra- } \\
\text { phy only as no active } \\
\text { bleeding was identi- } \\
\text { fied on first and third } \\
\text { angiographies. During } \\
\text { TAE, marked reduction } \\
\text { in contrast extravasa- } \\
\text { tion occurred. A minor } \\
\text { degree of extravasation } \\
\text { persisted and further } \\
\text { TAE avoided due to } \\
\text { perceived risk of signifi- } \\
\text { cant bowel ischemia. }\end{array}$ & $\begin{array}{l}\text { Laparotomy, di- } \\
\text { vision adhesions, } \\
\text { gastroscopy, small } \\
\text { bowel resection } \\
\text { for ongoing small } \\
\text { bowel bleed- } \\
\text { ing. Occurred } \\
2 \text { days post last } \\
\text { angiography. }\end{array}$ \\
\hline $\begin{array}{l}\text { 3. Recurrent } \\
\text { per-rectal } \\
\text { bleeding. } \\
\text { Associated } \\
\text { diverticular } \\
\text { disease and } \\
\text { antiplatelet } \\
\text { medication. }\end{array}$ & $\begin{array}{l}\text { TAE of a branch of the } \\
\text { left colic artery in the } \\
\text { mid-descending colon } \\
\text { with three } 2-3 \mathrm{~mm} \\
\text { platinum coils. Com- } \\
\text { pletion angiography } \\
\text { revealed hemostasis. }\end{array}$ & $\begin{array}{l}\text { Anterior resec- } \\
\text { tion for recurrent } \\
\text { diverticular } \\
\text { bleeds. Occurred } \\
8 \text { day post-TAE. }\end{array}$ \\
\hline
\end{tabular}

Abbreviation: TAE, transcatheter arterial embolization.

dataset; both were successfully treated with repeat TAE and packed red blood cell transfusion. The remaining four cases were all treated conservatively.

Two patients had colonoscopies during the admission following TAE for ongoing bleeding during which no active bleeding was found and no intervention occurred.

\section{Bowel Ischemia Requiring Surgery}

One patient underwent open hemicolectomy for bowel ischemia, which occurred 1 day following TAE for a bleeding cecal aneurysm. The patient was admitted with a 6-week history of melena. Gastroscopy at day 1 was normal. Colonoscopy at day 3 revealed a angiodysplastic lesion in the cecum that was treated with adrenalin and APC with good effect. TAE occurred at day 5 for ongoing bleeding. Hemorrhaging from a small bleeding aneurysm was arrested using superselective 2- to $3-\mathrm{mm}$ coils. Diffuse arterial spasm of the superior mesenteric artery branches was noted on initial angiography, which 
persisted throughout the procedure. On day 6 , the patient underwent a right hemicolectomy for bowel ischemia.

\section{Discussion}

Transcatheter arterial embolization for the management of GI hemorrhage is increasing ${ }^{13}$ and is now recommended for bleeding that is not controlled by, or appropriate for, medical or endoscopic therapy., ${ }^{4,514}$ This study provides evidence that TAE is a relatively safe and effective treatment modality for a diverse range of cases with intra-abdominal bleeding. Most procedures were technically successful, and only a small number of complications occurred, which were considered minor according to SIR classifications. ${ }^{12}$

Ischemia is the most common major complication of GI TAE, which is more common in the lower GI tract due to a higher portion of terminal branches compared with the upper GI tract's rich collateral blood supply. ${ }^{5,8}$ In our study, one patient required surgery to treat an ischemic bowel; however, attributing the ischemia to TAE is confounded by prior treatment with colonoscopy where adrenalin and APC were used, and the presence of diffuse arterial spasm on initial angiography prior to TAE.

Bowel ischemia has been reported in up to $33 \%$ of cases following TAE. ${ }^{7}$ Lower rates of ischemia have been reported in recent studies, which could be due to technological advancements and superselective embolization of more distal vessels, which reduces the risk of occluding multiple distal arteries that do not have sufficient collateral flow to compensate for occluded proximal branches. ${ }^{5,8}$ In a study similar to ours, one $(0.9 \%)$ patient had an ischemic bowel requiring surgery following TAE for lower GI bleeding. ${ }^{1}$ Yata et $\mathrm{al}^{15}$ found no endoscopic or histologic evidence of ischemia or intestinal necrosis in a sample of 39 patients treated with TAE for upper or lower GI bleeding.

Technical success rates of TAE for GI bleeding have been reported between 62 and 100\% (see Angle et al ${ }^{12}$ and Valek and Husty 5 for summaries). In our study, $94.6 \%$ of cases that had visible contrast media extravasation were successfully embolized, which is greater than the $90 \%$ recommended acceptable threshold for lower GI bleeding suggested by the SIR Standards of Practice Committee. ${ }^{12}$ Immediate cessation of bleeding could not be achieved in four of our cases. Ali et $\mathrm{al}^{1}$ indicated that technical failures are mainly due to difficult vascular anatomy, vascular stenosis, and vascular spasms, which was true for two of our cases. In the remaining two, the interventionalist deliberately stopped TAE prior to complete cessation of bleeding due to perceived risk of substantial ischemia; both these patients required surgical management to control bleeding.

Surgery for acute lower GI bleeding is generally considered after other therapeutic options have failed, and the quality of evidence regarding surgery for lower GI bleed is poor. ${ }^{4}$ Three (3.3\%) patients in this study underwent surgery for recurrent bleeding following TAE, which is similar to rates reported by others. ${ }^{1}$ Risk factors for recurrent bleeding are uncorrectable coagulopathy, older age, cirrhosis, oncologic diseases, multiple organ failure, and current corticosteroid treatment ${ }^{5}$; each of our surgical patients had one of more of these comorbidities.

\section{Strengths and Limitations}

Our study reviewed all intra-abdominal TAEs excluding gastric bleeding performed over a 7-year period at our institution. Data collection errors were reduced by using a standardized data collection template and having each case independently reviewed by two researchers who were medical doctors. This retrospective study is limited by the availability of data recorded in the patient's medical record. It is possible that minor complications were not assessed for and/or recorded in the medical record; for example, it is known that some patients will develop minor, asymptomatic, and self-limited ischemic changes, such as small ulcers that can only be detected via methods such as endoscopy. ${ }^{9}$ Patients with complications might have been cared for at other health care institutions whose records were not included in this investigation; three patients in our dataset were lost to follow-up as they were transferred to another hospital shortly after TAE. Adverse events occurring more than 30 days post-TAE were beyond the scope of this study (excluding death), though we expect most complications, particularly major complications including bowel infarction, would occur within this time frame. In this single-site study, three of the four interventional radiologists completed $97 \%$ of interventions, and our results might not be representative of outcomes at other institutions; however, the etiologies of bleeding were similar to other studies ${ }^{15}$ and most studies have not demonstrated variations in outcomes when differing techniques and materials were used. ${ }^{2}$

In conclusion, this study supports the use of TAE for intra-abdominal GI abdominal bleeding. Consistent with other studies, ${ }^{1,15}$ TAE produced high rates of immediate and complete hemostasis with low complication rates.

\section{Conflict of Interest}

None.

\section{Funding}

No funding was received to conduct this study.

\section{References}

1 Ali M, Ul Haq T, Salam B, Beg M, Sayani R, Azeemuddin M. Treatment of nonvariceal gastrointestinal hemorrhage by transcatheter embolization. Radiol Res Pract 2013;2013:604328

2 Mirsadraee S, Tirukonda P, Nicholson A, Everett SM, McPherson SJ. Embolization for non-variceal upper gastrointestinal tract haemorrhage: a systematic review. Clin Radiol 2011;66(6):500-509

3 Barkun AN, Bardou M, Kuipers EJ, et al; International Consensus Upper Gastrointestinal Bleeding Conference Group. International consensus recommendations on the management of patients with nonvariceal upper gastrointestinal bleeding. Ann Intern Med 2010;152(2):101-113

4 Strate LL, Gralnek IM. ACG clinical guideline: management of patients with acute lower gastrointestinal bleeding. Am J Gastroenterol 2016;111(4):459-474 
5 Valek V, Husty J. Quality improvement guidelines for transcatheter embolization for acute gastrointestinal nonvariceal hemorrhage. Cardiovasc Intervent Radiol 2013;36(3):608-612

6 Ramaswamy RS, Choi HW, Mouser HC, et al. Role of interventional radiology in the management of acute gastrointestinal bleeding. World J Radiol 2014;6(4):82-92

7 Khanna A, Ognibene SJ, Koniaris LG. Embolization as firstline therapy for diverticulosis-related massive lower gastrointestinal bleeding: evidence from a meta-analysis. J Gastrointest Surg 2005;9(3):343-352

8 Poultsides GA, Kim CJ, Orlando R III, Peros G, Hallisey MJ, Vignati PV. Angiographic embolization for gastroduodenal hemorrhage: safety, efficacy, and predictors of outcome. Arch Surg 2008;143(5):457-461

9 Walker TG. Acute gastrointestinal hemorrhage. Tech Vasc Interv Radiol 2009;12(2):80-91

10 American College of Radiology (ACR) Committee on Appropriateness Criteria. ACR Appropriateness Criteria: Radiologic Management of Lower Gastrointestinal Tract Bleeding 2014. Cited in January 2018. https://www.acr.org/ Clinical-Resources/ACR-Appropriateness-Criteria

11 Harris PA, Taylor R, Thielke R, Payne J, Gonzalez N, Conde JG. Research electronic data capture (REDCap)-a metadata-driven methodology and workflow process for providing translational research informatics support. J Biomed Inform 2009;42(2):377-381

12 Angle JF, Siddiqi NH, Wallace MJ, et al; Society of Interventional Radiology Standards of Practice Committee. Quality improvement guidelines for percutaneous transcatheter embolization: Society of Interventional Radiology Standards of Practice Committee. J Vasc Interv Radiol 2010;21(10):1479-1486

13 Loffroy RF, Abualsaud BA, Lin MD, Rao PP. Recent advances in endovascular techniques for management of acute nonvariceal upper gastrointestinal bleeding. World J Gastrointest Surg 2011;3(7):89-100

14 Gralnek IM, Dumonceau JM, Kuipers EJ, et al. Diagnosis and management of nonvariceal upper gastrointestinal hemorrhage: European Society of Gastrointestinal Endoscopy (ESGE) guideline. Endoscopy 2015;47(10):a1-a46

15 Yata S, Ihaya T, Kaminou T, et al. Transcatheter arterial embolization of acute arterial bleeding in the upper and lower gastrointestinal tract with $\mathrm{N}$-butyl-2-cyanoacrylate. J Vasc Interv Radiol 2013;24(3):422-431 